\title{
EFFECT OF SIZE MATERIAL ON JUTE-COTTON UNION FABRIC
}

\author{
Md. Abul Kalam Azad and Shamina Jafrin \\ Pilot Plant and Processing Division \\ Bangladesh Jute Research Institute, Dhaka, Bangladesh \\ E-mail: sjafrin@gmail.com
}

\begin{abstract}
A study was performed on the jutecotton union fabric to show the effect of sizing on the properties of union fabric. Here, the cotton yarn was used in the warp direction and jute yarn was used in the weft direction. The size material was used only for warp yarn that is for cotton yarn. From the experimental results, it was seen that the strength of the sized union fabric was better than the unsized union fabric although the other properties were similar to each other. Comparing the properties of union fabric with $100 \%$ cotton fabric, union fabric (jute-cotton) may be the replacement of $100 \%$ same category of cotton fabric.
\end{abstract}

Key words: Jute, union fabric, cotton fabric, warp yarn, weft yarn, sized, properties.

\section{Introduction}

Jute is a lignocellulosic bast fibre. It is a coarse fibre of harsh character. The present of cellulose percentage is lower than that of cotton. On the other hand, hemicellulose is an important chemical component which is present in jute. Due to present of hemicellulose and lignin, jute is more stiff and yellowish colour than cotton. Jute is the cheapest commercial fibre [1]. Jute is mainly used in manufacturing packing and coarse fabric such as hessian, sacking, carpet, carpet backing cloth etc. But in course of time it has therefore become necessary to find out alternative uses of jute for relating the economic viability of Jute Industry and thereby supporting million of people who live on it. Jute fibre conventionally is not used for producing textile products as it has some shortcoming in regard to feel, stiffness, drape, coarseness wash ability and abrasion. The stiffness or hardness of fabric has great impact on its bending length or drape coefficient [2].

During weaving, size materials plays and important role for the warp yarn. The protruding fibres of the warp yarn are diminished due to sizing [3]. Sized yarn is stronger than the unsized yarn and with stand the friction of yarns during weaving [4].

Various types of size materials are used in the warp yarn. Among them tamarind seed powder and any type of starch are mainly used for jute and cotton. These are available and cost effective.

For union fabric generally cotton yarn is used in warp direction and jute yarn is used in weft direction. Union fabrics are cheaper than $100 \%$ cotton fabric due to use of jute in it. Jute-cotton union fabric has the prospect of wider uses and likely to come popular industrial producet. The bending length of a fabric is a length at which fabric will bend under its own weight to a definite extent [5]. It is a measure of stiffness that determines draping quality. Size material has also a strong influence on bending length. Higher the stiffness of the fabric higher the bending length [5]. On the other hand, assessment of abrasion damage is determined in terms of appearance against a unabrabbed specimen, which causes loss in weight, loss in strength and change in lusture [6].

Through development studies, this work has been taken to find out the effect of size material on the properties of union fabric.

\section{Materials and Methods}

The union fabric used in this experiment is made from jute and cotton. The cotton and jute yarns are used in the warp and weft direction respectively. The cotton yarn of $10^{\mathrm{s}}$ count is collected from the local market and sized with the starch material. Due to sizing, the haireness of the yarn is not removed but diminish a lot for successful weaving. Sized yarn can also with stand the friction of warp yarns during weaving. Jute yarn of $6 \mathrm{lbs} / \mathrm{spy}$ is collected from the spinning department of Bangladesh Jute 
Research Institute (BJRI). It is used in weft direction without using size material. For weft yarn, size material is not used due to less or without friction. The weft yarn is used in spool form and it is also made in spinning department of BJRI. Before weaving, the warp beam was prepared by the beaming machine. Starch was used in the warp yarns as size material during beaming. A normal power loom was used to produce union fabric. The union fabric was produced from the Yarn and Fabric Production Department of Pilot Plant and Processing Division of BJRI. Lastly, the physical properties of the fabric through various treatments were tested in the Testing Department of Bangladesh Jute Research Institute (BJRI).The bending length is a measure of stiffness associated with handle. The bending length is determined by the "Shirley Stiffness Tester" which shows a close relationship between this value and the personal judgment of stiffness [7]. The strength of the fabric was determined by the "Tensile Strength Tester" of Good Brand Co. Ltd. The abrasion resistance of the fabric was determined by the "Abrasion Tester". The haireness of sized and unsized yarn was tested by the "Zooglee Haireness Tester."

\section{Results and Discussions}

All the tests were performed in the standard testing atmosphere i,e $65 \pm 2^{\circ}$ r,h and 20 $\pm 2^{\circ} \mathrm{C}$. The results are shown in the Table 1 and 2. From the Table 1, it is seen that count of the weft yarn of jute was $6 \mathrm{lb} / \mathrm{spy}$ and count of warp yarn of cotton was $10^{\mathrm{s}}$. Quality ratio of the jute yarn was good (91.66\%). Count strength product (C.P.S) of the cotton yarn was also acceptable (1670).

Table 2 shows that warp count of the grey fabric were same both in the union fabric (jute-cotton) and $100 \%$ cotton fabric. Pick/inch of the union fabric and 100\% cotton fabric was 21 and 25 respectively. It was observed that wt/sq.m of the union fabric was higher than the $100 \%$ cotton fabric. Wt./sq.m were gradually decreased with the different treatment process of both types of fabrics. This is due to loss of sizing material from the fabrics. Warp wise tensile strength of the union fabrics was higher than the weft wise. But weft wise tensile strength of $100 \%$ cotton fabric was higher than the weft wise strength of union fabrics. Warp and weft wise strength were gradually decreased by the different treatment process. At first bending length of the union fabric \& $100 \%$ cotton fabric was 3.6 and 3.1 respectively. After subsequent treatment bending length of the union fabrics were higher than the $100 \%$ cotton fabrics. Abrasion resistance of the union fabric and $100 \%$ cotton fabric was excellent at all the time. From the above result, it was observed that the property of jute cotton union fabric is increased by using sizing materials.

\section{Conclusion}

Jute is a bio-degradable and environment friendly natural fibre. It is free from health hazard. Due to these good properties, jute fabrics have considerable demand in house and abroad. At the same time, price of the $100 \%$ cotton fabric higher than the jutecotton union fabric. That's why union fabric may be the replacement of $100 \%$ cotton fabric.

Tensile strength of the union fabric was higher and hairiness of the union fabric was decreased by using sizing material. Sized union fabric was durable and smooth like $100 \%$ cotton fabric. Union fabric was cost effective than the $100 \%$ cotton fabric. That is why the demand of sized union fabric is increasing day by day instead of $100 \%$ cotton fabric. Hence the use of jute is also increasing through diversified jute products.

Table 1 Physical properties of warp and weft yarn of union fabric

\begin{tabular}{|r|l|l|l|}
\hline Sl. No. & Parameter & Jute yarn (weft) & \multicolumn{1}{c|}{ Cotton yarn (warp) } \\
\hline 1. & Count & 6 lbs/spy & $10^{\text {s }}$ \\
\hline 2. & Strength & $\begin{array}{l}5.5 \mathrm{lbs} \\
\text { (Single yarn) }\end{array}$ & $\begin{array}{l}167 \mathrm{lbs} \\
\text { (Lea strength) }\end{array}$ \\
\hline 3. & T.P.I & 5 & 16 \\
\hline 4. & Haireness & - & $280 / \mathrm{m}$ for sized yarn, 350/m for unsized yarn \\
\hline 5. & Quality ratio & 91.66 & - \\
\hline 6. & C.S.P & - & 1670 \\
\hline
\end{tabular}


Table 2 Comparative properties of sized union fabric and 100\% cotton fabric at different treatments

\begin{tabular}{|c|c|c|c|c|}
\hline $\begin{array}{l}\text { Sl. } \\
\text { No. }\end{array}$ & Treatments & Observations & $\begin{array}{l}\text { Union fabric (jute- } \\
\text { cotton) }\end{array}$ & $100 \%$ cotton fabric \\
\hline \multirow[t]{9}{*}{1.} & \multirow{9}{*}{ Grey fabric } & Warp count & $10^{\mathrm{s}}$ & $10^{\mathrm{s}}$ \\
\hline & & Weft count & $6 \mathrm{lb} / \mathrm{spy}$ & $10^{\mathrm{s}}$ \\
\hline & & End/inch & 34 & 40 \\
\hline & & Pick/inch & 21 & 25 \\
\hline & & Wt/sq.m (gm) & 386.6 & 338.2 \\
\hline & & Warp wise strength (kg) & 138.2 & 139.4 \\
\hline & & Weft wise strength(kg) & 129.6 & 131.3 \\
\hline & & Bending length (cm) & 3.6 & 3.1 \\
\hline & & Abrasion resistance & very excellent & very excellent \\
\hline \multirow[t]{5}{*}{2.} & \multirow{5}{*}{$\begin{array}{l}\text { Desized } \\
\text { fabric } \\
\text { (Simple soap } \\
\text { wash) }\end{array}$} & wt./sq.m(gm) & 341.2 & 318.3 \\
\hline & & Warp wise strength(kg) & 121.6 & 122.2 \\
\hline & & Weft wise strength(kg) & 120.2 & 129.2 \\
\hline & & Bending length (cm) & 3.1 & 2.9 \\
\hline & & Abrasion resistance & excellent & excellent \\
\hline \multirow[t]{5}{*}{3.} & \multirow{5}{*}{$\begin{array}{l}\text { Enzyme } \\
\text { Wash }\end{array}$} & wt./sq.m (gm) & 338.0 & 317.2 \\
\hline & & Warp wise strength (kg) & 120.1 & 121.2 \\
\hline & & Weft wise strength (kg) & 118.0 & 127.6 \\
\hline & & Bending length (cm) & 3.0 & 2.8 \\
\hline & & Abrasion resistance & excellent & excellent \\
\hline \multirow[t]{5}{*}{4.} & \multirow{5}{*}{$\begin{array}{l}\text { Bleach and } \\
\text { enzyme wash } \\
\left(15 \% \mathrm{H}_{2} \mathrm{O}_{2}\right)\end{array}$} & wt./sq.m(gm) & 332.6 & 315.5 \\
\hline & & Warp wise strength (kg) & 118.2 & 121.0 \\
\hline & & Weft wise strength (kg) & 114.3 & 125.1 \\
\hline & & Bending length (cm) & 2.8 & 2.7 \\
\hline & & Abrasion resistance & excellent & excellent \\
\hline \multirow[t]{5}{*}{5.} & \multirow{5}{*}{$\begin{array}{l}\text { Bleach, } \\
\text { enzyme, } \\
\text { wash and } \\
\text { softening (10 } \\
\text { gm/l } \\
\text { basosoft) }\end{array}$} & wt./sq.m(gm) & 320.5 & 310.4 \\
\hline & & Warp wise strength (kg) & 111.6 & 115.2 \\
\hline & & Weft wise strength (kg) & 108.2 & 122.5 \\
\hline & & Bending length (cm) & 2.6 & 2.4 \\
\hline & & Abrasion resistance & excellent & excellent \\
\hline
\end{tabular}

\section{References}

[1] Mathews, I.M. Mathews Textile Fibres, Herbert R, Nauer berger, New York,

[2] John Wiley and Sons. PP: 325-335.1947.

[3] Bell,WA, Jute Fabric for Upholstery and curtain. BJTRA 12. PP:12-25, 1968

[4] Atkinson, R.R, Jute Fibre to yarn Haytood Books London.P.P-139.1964.
[5] Vanghaluwe, L. Mechanism of weaving. Head of Weaving Deptt. Gent

[6] University, Belgium. PP-86.1995.

[7] Booth, J.E Principles of Textile Testing. PP : 288253.1979.

[8] Chu.C.C.Cummneing C.L.and Texijca N.A, Physical properties of cotton upholstery.J.Text.: Res. 1960. 20:39.

[9] Textile Research journal. 1951. pp. 21. 